\title{
NEUROVASCULAR SYNDROMES OF THE SHOULDER GIRDLE AND UPPER EXTREMITY: THE COMPRESSION DISORDERS AND THE SHOULDER-HAND SYNDROME
}

\author{
By H. Harold Friedman, M.D., Thomas G. Argyros, M.D., and Otto Steinbrocker, M.D.*
}

\section{Introduction}

Some of the most perplexing and difficult musculoskeletal disorders are included among those affecting the shoulder girdle and upper extremity. Pain, paresthesias, hyperesthesia and vasomotor disturbances may occur in any of them, but these symptoms in combination are characteristic of few, chiefly the neurovascular syndromes. The interpretation and differentiation of the clinical features may embrace a large number of diseases and disorders (Table $\mathrm{r}$ ). The purpose of this paper is to summarize present knowledge of two groups of these conditions-the reflex neurovascular disorders, as fully exemplified by the shoulder-hand syndrome, and the compression neurovascular syndromes (" thoracic outlet syndromes'). Since anatomic factors are of basic importance in the genesis of these disturbances, the pertinent anatomy must be visualized in these problems (Fig. I).

\section{Anatomy}

The anatomy is complex, so only its main features will be mentioned here. The normal components of this area include the first rib, the scalene muscles (anterior, medial, occasionally inferior), clavicle and subclavius, the coracoid process and pectoralis minor muscle. Added to these at times may be encountered bony deformities of the first rib and the clavicle, cervical ribs, gross deformities due to kyphoscoliosis, thoracoplasty and injury, bizarre insertions of the scalene muscles and assorted congenital fibrous bands, vascular anomalies, lymph node enlargements, tumours, etc. ${ }^{11}$ The key to the whole problem consists of the size and the adaptability of the thoroughfare, the thoracic outlet and its contiguous space, through which the neurovascular bundle must pass in close relationship to the

\footnotetext{
*From General Rose Memorial Hospital and the University of Colorado Medical Center, Denver, Colorado (Dr. Friedman) and the Rheumatology Department, Hospital for Joint Diseases and Lenox Hill Hospital, N.Y.C. (Drs. Argyros and Steinbrocker).
}

anatomic constitutents already mentioned. In the vast majority of people this short distance is traversed without difficulty, even in the presence of anomalous structures. In some, however, the bundle is impinged upon, in one way or another, to produce the symptoms underlying the syndromes under discussion.

Normally, the subclavian artery hooks up and over the first rib, lying between the insertions of the scalenus anterior and medius muscles, passes down under the coracoid process and then into the axilla. The subclavian vein runs a parallel route, except that it proceeds between the scalenus anterior and the clavicle. The brachial plexus in this region tends to course along the artery and is represented primarily by fibers from C8-TI. The prominent points of compression have given their names to the syndromes they provoke. At present, these include the cervical rib, scalenus anticus, first rib and costoclavicular syndromes. The hyperabduction syndrome might be regarded, accordingly, as the 'coracoid pectoralis minor clavicle syndrome.'

\section{Contributory or Provocative Factors}

Contributing factors in the production of symptoms include the great mobility of the shoulder which, even in normal structures, permits compression of the neurovascular bundle in certain positions. Generally, these are responsible for symptoms only when there is prolonged maintenance of bizarre positions, as in work, sleep, recreation, etc. As people age there is a tendency toward a reduction in muscle mass and a loss of tone with a drooping of the shoulders. Anomalies and trauma play an obvious role. Arteriosclerosis with loss of pliability is a frequent predisposing factor to vascular complication from compression in the older age groups.

\section{Symptomatology of the Compression Syndromes}

The clinical manifestations of these syndromes are dependent upon compression of the brachial 


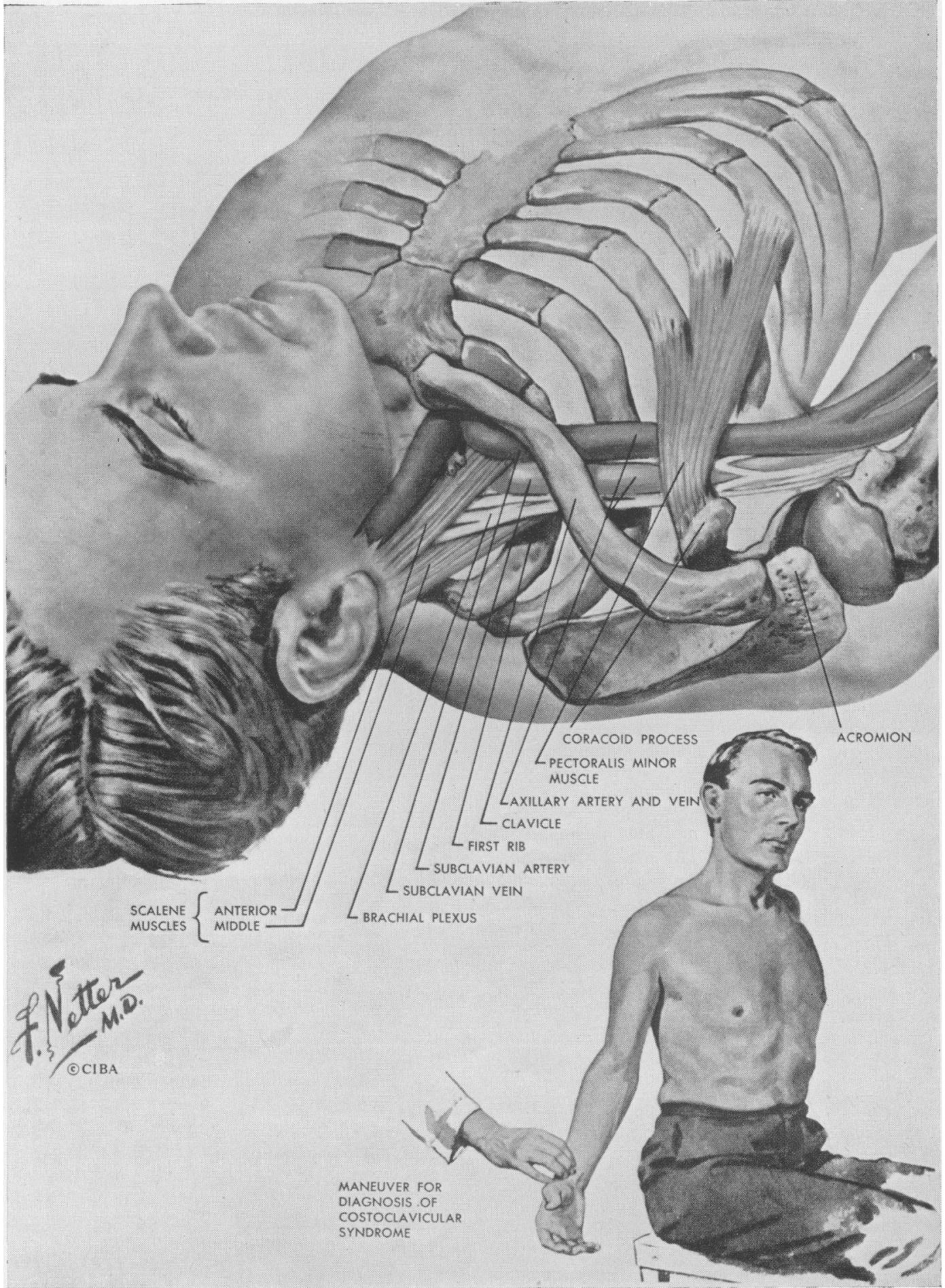

Fig. r.-Essential anatomy of the shoulder girdle, especially the costoclavicular space, and diagnostic manoeuvre for costoclavicular syndrome.

Courtesy, Fere W. Lord, $\mathscr{F r}$., M.D., and Louis M. Rosati, M.D., Clinical Symposia, 10, 2, 1958. 
TABle I

Disorders with Neural, Vascular and Neurovascular Features at the Shoulder and Upper Extremitt

Neurovascular Disorders

Compression Syndromes

Cervical rib, scalenus or first rib syndrome

Costoclavicular syndrome

Hyperabduction syndrome

Reflex neurovascular syndromes

Shoulder-hand syndrome

Circumscribed reflex dystrophy (Sudeck's atrophy, causalgia, etc.)

\author{
Vascular Disorders, Predominantly \\ Arterial \\ Acute arterial occlusion \\ Chronic occlusive arterial disease \\ Aneurism \\ Erythromelalgia \\ Raynaud's disease \\ Arteriovenous fistula \\ Venous \\ Acute thrombophlebitis \\ Chronic venous insufficiency \\ Lymphatic \\ Acute lymphangitis \\ Chronic lymphedema
}

plexus and $/$ or vascular structures and the radiation or referral of pain from the structures compressed. Vascular symptoms are frequently absent, sometimes prevail, and occasionally are the only ones present. Neurologic symptoms and signs are presented more often than those of vascular origin. They may be either sensory or motor, or both. Pain at the shoulder or along the extremity may be described. Local tenderness may be elicited by palpation at the sites of complaint. Symptoms, therefore, may be essentially musculoskeletal, neurologic, vascular or any combination of them.

Pain and paresthesias are the predominant symptoms in most cases, but they are variable. Pain in the shoulder and deltoid regions with radiation to the elbow is a not uncommon complaint. Frequent, also, is pain felt in the ulnar aspect of the forearm and hand in the fourth and fifth fingers. Sometimes the pain spreads to the radial aspect of the forearm, hand and fingers; to the head, neck and face; and to the scapular area or chest. The pain is generally described as being of an aching or shooting nature.

While the pain in these syndromes may occur during the course of the day's activities it has a decided tendency to become worse at night, particularly when the patient is lying down. There often is difficulty in falling asleep and, if asleep, the patient is apt to be awakened by the discomfort. Whenever pain occurs, the patient attempts to find relief by adopting different positions. Sometimes the symptoms are alleviated by lying prone and permitting the arms to
Neurological Disorders, Predominantly

Spinal cord trauma

Syringomyelia

Protruded intervertebral disk

Neuropathy or tumours of the brachial plexus or cervicodorsal nerves

Herpes zoster

Nocturnal dysthesias

Brachalgia paresthetica

Acroparesthesias

Carpal tunnel syndrome

Systemic Diseases with Local Features

Diffuse vasculitis

Relapsing nodular panniculitis

Rheumatoid arthritis

Osteoarthritis of the cervical spine and shoulder

Dermatomyositis

Scleroderma

Other Disorders

Fibromyalgias of the neck and shoulder

Intrinsic lesions of the shoulder

Bicipital tendovaginitis

Calcific tendinitis

Periarthritis of the shoulder

Psychalgias

swing over the side of the bed. At other times, relief is obtained by elevating the shoulders, as in leaning forward on the elbows, or by bending the neck toward the affected side, a position which reduces the drag on the brachial plexus. Some patients are more comfortable with the arms adducted and with the forearm and hands placed across the chest.

The pain is generally aggravated by activities which involve the use of the arms and shoulders such as lifting, reaching or pushing. Activities which depress the shoulder, such as carrying suitcases or heavy objects, also are likely to intensify symptoms. Deep inspiration and hyperextension of the neck often increase the discomfort.

There is usually a paucity of objective neurological signs. Sensory changes, such as hyperesthesiae, are infrequent. When present, they tend to occur in the distribution of the median or ulnar nerves. Such motor abnormalities as weakness, atrophy and muscle twitchings, are likewise found in similar distribution. ${ }^{26}$ In rare instances, in the presence of a cervical rib, a Horner's syndrome provides evidence of involvement of the cervical sympathetic fibers.

The vascular changes which occur in these syndromes include: (I) coldness, pallor and cyanosis of the hand; (2) swelling of the hand(s); (3) dependent rubor; (4) gangrene and ulcerations of the finger tips; (5) classical Raynaud's phenomenon $^{2}$; and (6) complications such as axillary vein or subclavian artery thrombosis and 
aneurysm of the subclavian artery with or without occlusion of the vessel.11

In an affected extremity, the pulse is more easily obliterated than in the normal person, by various manoeuvres to be discussed. An arterial bruit may be heard in the supraclavicular space. ${ }^{4}$. Cervical ribs, if present, can often be palpated in this region. Sometimes the blood pressure will be found to be lower on the affected side.

\section{The Compression Syndromes of the Shoulder Cervical Rib, Scalenus Anticus and First Rib Syndrome}

Historically, the first of these to be described was the cervical rib syndrome. Cervical ribs occur as anomalous appendages in approximately 0 to 0.05 per cent. of individuals, with more than half being bilateral. They are two to three times more common in women. Usually they are incidental findings, with only some ro per cent. of them causing any difficulty. The size, shape and insertion of the rib will frequently be the determining factors in the production of symptoms. Often there is arterial compression, with poststenotic dilatation and incipient thrombosis. The scalenus muscles may or may not be important in the activation of symptoms. Their participation, however, frequently cannot be determined with certainty preoperatively. The approach to these problems, in the more severe cases, has been surgical removal of the rib, initiated by Coste in $1861 .^{25}$ This procedure, although surgically sound, too often was attended by vârious complications which resulted in equally severe symptoms, sometimes worse. $\mathrm{Law}^{25}$ in 1920, and Adson and Coffey in 1927, suggested resection of the scalenus anticus muscle as an easier method of decompression. They found in an impressive series that simple tenotomy was quite effective. Today, scalenotomy is performed, with partial resection of the rib, if necessary. The precipitating factors in the production of symptoms probably are those mentioned among the contributory factors, since most patients do not present symptoms until they reach the 20- to 40-year age group.

Numerous workers during the past 50 years have been impressed by the presence of the 'cervical rib syndrome in the absence of cervical rib.' Observers during the $1903-1917^{13}$ period attributed these cases to stretching of the brachial plexus over the first rib due to dropping of the shoulder girdle from an increased lateral diameter of the chest with age. In 1933 Adson suggested the possible responsibility of the scalenus anticus muscle and in 1935 the 'scalenus anticus syndrome' was given its present formulation by Naffziger and Grant, ${ }^{14}$ as well as Ochsner, Gage and DeBakey. ${ }^{15}$ The basic concept is the de- duction that, in the presence of a normal shoulder girdle, the scalenus anticus muscle compresses the neurovascular bundle against the first rib and a normal scalenus medius through a process of $c$. spastic irritability and hypertrophy. Their theory $\vec{F}$ holds that the scalenus anticus is irritated in some fashion, so bringing about its spasticity, whereby it compresses the brachial plexus. This compression reflexly increases the spasm of the scalenus anticus. These reactions are believed to produce a vicious circle. The corollary, in the thesis of the originators, is breaking the circle by sectioning the scalenus anticus muscle.

Diagnosis of a scalenus anticus syndrome was based on evidence of a tender scalenus anterior, the dampening of the pulse of the affected extremity by certain manoeuvres, especially the Adson routine* and the partial relief of symptoms by procaine injection of the scalenus anticus muscle. ${ }^{10}$ This clinical formulation was followed by a cycle of favourable reports on the resection of the anterior scalene muscle. In time, however, subsequent observers indicated frequent failures. These led to further critical evaluation, with the elucidation of other mechanisms of the compression. The initial concept has been challenged on several grounds by many clinicians. Walshe ${ }^{26}$ feels thas most of these disorders really are instances of firs rib syndrome. Others hold that the size of the scalenus is variable, that infiltration with procain $\overrightarrow{\vec{e}^{+}}$ frequently spills over and produces a sympathetic block of the stellate ganglion with a Horner's syndrome, or that the solution may even flow over to the brachial plexus with relief of pain. Dampening of the pulse is not regarded as specific. The absence of any spasm or change in the similarly innervated scalenus medius is thought to remain unexplained by this theory. Finally, the possibility has been suggested that the tenderness is not definitely indicative of scalenus origin, but may arise from underlying structures. The general view of observers today is that the scalenus anticus syndrome, as postulated in the I93os, remains unproved and that relief of symptoms by surgical tenotomy is secondary to simple de- $\rightarrow$ compression of the neurovascular bundle. This relief, according to present views, arises from the removal of one arm of a passive vise, or to the simpler fact that the patient receives, together with the surgery, a period of bed rest and change in usual habits. The more severe symptomatic failures, when restudied, often were found to have other mechanisms or sources of compression.

*The Adson manoeuvre is carried out with the patient upright and the examiner's fingers on the radial pulse of the tested extremity, which is held at the side of the subject who takes a deep breath and holds it, then turns the head to the side tested. 


\section{Costoclavicular Syndrome}

In I943, Weddel and Falconer ${ }^{5}$ described the costoclavicular syndrome. In restudying three cases of scalenotomy failure, they found the principal site of compression located between the clavicle and the first rib. They were able to demonstrate that backward and downward bracing of the shoulders, as in the exaggerated military posture, would approximate the two bony structures and compress the neurovascular elements. That this mechanism could occur in a normal shoulder had been appreciated by earlier workers. It has been reaffirmed by Wright and Lord ${ }^{18}$ and by Walshe. ${ }^{26}$

This syndrome was common during the last World War, when heavy packs could not be worn by many men owing to the severe pain, paresthesias, venous congestion and edema which would develop, due to direct costoclavicular compression. ${ }^{5,19}$ Interestingly, many of these young soldiers were able to sustain the packs following six to eight weeks of army life and training. ${ }^{19}$ In the absence of deformities or exogenous factors this is not a common syndrome. Walshe, however, cites repetitive costoclavicular compression as a frequent contributor to symptoms. ${ }^{26}$ Telford and Mottershead were unable to demonstrate compression by simple depression of the shoulder, but in their work they do not comment on whether they retracted the shoulder as well. ${ }^{23}$ (The pulse can be dampened in some 60 per cent. of people by an exaggerated military posture. $)^{19}$

\section{Hyperabduction Syndrome}

Wright described the mechanism of the hyperabduction syndrome in $1945 .{ }^{28,2}$ In this group of patients with clear-cut neurovascular symptoms, mostly of a vascular nature, the principal points of compression were found to be under the coracoid process and between the clavicle and first rib. The symptoms were demonstrated to occur by laterally circumducting the arms and clasping the hands over the head. The neurovascular bundle becomes taut as it crosses the coracoid process and the head of the humerus. It is further compressed by the clavicle and the muscular action of the pectoralis minor. Some reduction of the pulse by this manoeuvre has been observed in 60 to 80 per cent. of normal individuals. The original paper reported on eight patients in whom the principal factor was this persistent posture in sleep. ${ }^{28}$ Symptoms were relieved by a change in the habit. Most individuals affected have been found to maintain a hyperabducted position of the extremity in sleep, recreational activities or in certain occupations-ballet dancers, painters, grease pit mechanics and others. Subsequent observations also have shown the presence of
Raynaud's phenomenon in about 50 per cent. of the patients. In some cases symptoms included superficial gangrene of the finger tips which healed readily, when the provocation was eliminated.28,2

\section{Management of Compression Syndromes}

The management depends upon the cause and the severity of symptoms, as well as the major point of compression. Where postural or exogenous factors play a role, such as pushing, pulling, lifting, carrying heavy objects, etc., simple corrections may relieve the symptoms. When shoulder drooping is due to poor posture, age and related factors, muscle development may be indicated. Physical therapy in the form of heat and the use of analgesics may help resolve residual soreness of muscles. Structural deformities of the bony, muscular or other tissues may require surgical decompression. When surgery is performed, the current trend is to do a thorough exploration in order to adequately decompress the neurovascular canal by combined procedures, where necessary-scalenotomy with clavicular removal; possibly resection of the first rib or of the cervical rib; or section of the pectoralis minor muscle in some cases.

\section{The Shoulder-Hand Syndrome Nature of the Syndrome}

The shoulder-hand syndrome is a reflex neurovascular disorder, often termed ' reflex neurovascular dystrophy,' characterized by painful disability of the shoulder preceding, accompanying or following painful disability, vasomotor changes, with swelling, or dystrophic alterations in the later phases, at the hand and fingers. This condition is seen largely in the older age groups, in medical disorders, arising often from etiologic factors encountered in the later decades of life. The symptom-complex develops in most patients so closely after external trauma or internal lesions, such as myocardial infarction, that the etiologic relationship seems obvious. A multiplicity of designations ('Table 2), according to the observers' viewpoints, have obscured the clinical similarity of the physiologic disturbance and symptoms, whether they originate in external trauma or internal violence to tissue.

Symptomatology of the Shoulder-Hand Syndrome

The clinical picture has been divided roughly into three stages (Table 3 ). In the first phase the essential features consist of pain and disability of the shoulder, of insidious or sudden onset, which frequently is thought to be a bursitis or periarthritis. Usually, a short time after (sometimes simultaneously or before) the appearance of the shoulder symptoms, a sudden or gradual onset of 
TABle 2*

Terminology of the Various Reflex Nburovascular Syndromes Often Described as Special Entities

Neurological and Neurosurgical

Peripheral Nerve Injuries

Causalgia

Phantom limb

Spinal and Central Lesions

Thalamic syndrome

Cerebrospinal pain syndromes

Shoulder-hand syndrome

\section{Internal Lesions}

Changes in pareticlimbs of hemiplegics

Neurotrophic rheumatism

Painful disability of the shoulder (and hand) after coronary occlusion

Post-infarction sclerodactylia

Swollen atrophic hand with cervical osteoarthritis

Shoulder-hand syndrome
Traumatic and Post-traumatic

Acute bone atrophy

Minor causalgia

Post-traumatic arteriospasm

Post-traumatic edema

Post-traumatic osteoporosis

Post-traumatic spreading neuralgia

Post-traumatic sympathalgia

Post-traumatic trophoneurosis

Post-traumatic vasomotor syndrome

Reflex dystrophy

Reflex hyperemic deossification

Reflex sympathetic dystrophy

Sudeck's atrophy

Sympathetic trophoneurosis

Shoulder-hand syndrome

*From the Shoulder-Hand Syndrome: Present Status as a Diagnostic and

Therapeutic Entity Medical Cr. N.A., November, 1958.

TABLE 3*

Clinical Evolution of the Shoulder-Hand Syndrome

\begin{tabular}{|c|c|c|}
\hline Stage I & Stage 2 & Stage 3 \\
\hline $\begin{array}{l}\text { Shoulder } \\
\text { Pain } \\
\text { Disability in all ranges } \\
\text { Tenderness, diffuse (localized } \\
\text { early) } \\
\text { Osteoporosis, patchy at humeral } \\
\text { head sometimes }\end{array}$ & $\begin{array}{l}\text { Pain and disability resolving or } \\
\text { persisting } \\
\text { Possible atrophy of muscles } \\
\text { Osteoporosis, patchy then ground- } \\
\text { glass }\end{array}$ & $\begin{array}{l}\text { Residual pain infrequently } \\
\text { Disability sometimes } \\
\text { Ground-glass, diffuse osteoporosis }\end{array}$ \\
\hline $\begin{array}{l}\text { Hand and Fingers } \\
\text { Pain } \\
\text { Tenderness, diffuse } \\
\text { Cutaneous hyperesthesia } \\
\text { Disability } \\
\text { Massive dorsal swelling }\end{array}$ & $\begin{array}{l}\text { Symptoms resolving or continuing } \\
\text { with early dystrophic changes } \\
\text { Often induration of cutis and } \\
\text { subcutis }\end{array}$ & $\begin{array}{l}\text { Persistent pain, rarely } \\
\text { Residual dystrophy and contractures }\end{array}$ \\
\hline $\begin{array}{l}\text { Digital Changes } \\
\text { Dermal swelling, diffuse } \\
\text { Sometimes early, shiny cutis and } \\
\text { trophic changes as in next stage } \\
\text { Incomplete, painful digital flexion }\end{array}$ & $\begin{array}{l}\text { Firm induration with obliteration } \\
\text { of dorsal skin creases } \\
\text { Shiny, trophic skin surface } \\
\text { Trophic nail changes initiated } \\
\text { sometimes } \\
\text { Dorsal hypertrichosis sometimes } \\
\text { Resolving or impending digital } \\
\text { atrophy and contractures }\end{array}$ & $\begin{array}{l}\text { Rarely increased } \\
\text { Dull, diffuse atrophy of skin and } \\
\text { subcutis } \\
\text { Marked occasionally } \\
\text { Increased sometimes } \\
\text { Residual contractures and dis- } \\
\text { tortions }\end{array}$ \\
\hline $\begin{array}{l}\text { Vasomotor Changes } \\
\text { Vasodilatation or vasospasm } \\
\text { Colour changes } \\
\text { Hyperhidrosis at palms }\end{array}$ & $\begin{array}{c}\text { Vasospasm often with hyper- } \\
\text { hidrosis }\end{array}$ & $\begin{array}{l}\text { Vasomotor imbalance occasionally } \\
\text { Usually absent with dystrophic } \\
\text { changes }\end{array}$ \\
\hline $\begin{array}{l}\text { Roentgenographic } \\
\text { Spotty osteoporosis of humeral } \\
\text { head, wrist }\end{array}$ & More marked & $\begin{array}{l}\text { Ground-glass diffuse osteoporosis of } \\
\text { humeral head. wrist and fingers }\end{array}$ \\
\hline
\end{tabular}


painful disability of the hand and fingers develops, marked by swelling of the latter, pain on passive motion of hand joints, loss of skin wrinkles, inability to flex the fingers, and often spotty osteoporosis of the carpus in films. The first stage may last up to three to six months. It may gradually resolve, spontaneously, but may progress to the second stage. The pain in the shoulder gradually subsides, the swelling of the hand decreases, possibly with increasingly painful and limited mobility; sometimes with a Dupuytren-like thickening at the palm, often with coldness of the hand and some degree of dystrophic skin changes. This phase may gradually merge into the final stage with the production of a 'fibrosed,' distorted hand with contracted fingers, a 'frozen shoulder' and an impaired extremity. The process may stop anywhere along this line of progression, spontaneously or as a result of treatment.

\section{Etiology and Mechanism of the Shoulder-Hand Syndrome}

The etiology remains obscure in some 30 per cent. of our carefully studied cases in which it must be classified as 'idiopathic.' Severe or minor trauma to limbs, myocardial infarction, pericarditis, hemiplegia, cervical osteoarthritis and disc changes, brain tumours and many internal lesions, with neural or segmental connections to the upper extremity, have been implicated. However, the sequence of events in the many conditions with which there is a frequent association suggests a common pathway of production of symptoms. The concept most widely held today is that of a traumatic focus, internal or external, with a channelling of stimulating impulses to the cervico-thoracic spinal cord.

According to this widely regarded theory, the normal physiology of the 'internuncial pool' of neurons at the level of local injury is disturbed. From the site of the lesion through the internuncial communications, along the pathways of the autonomic and motor systems, the symptomproducing neurovascular impulses reach the periphery of the upper extremity. Once the syndrome has been produced by the injury or lesion, a self-perpetuating mechanism or 'feedback' is set up via the afferent, sensory fibers to the internuncial pool with short and long reverberating 'closed loop' relays of neurological impulses in the 'pool,' which are thought to keep the process going until it runs its course. This is one of several, different, helpful working concepts. There are, nevertheless, many unknown facets of this group of disorders leaving great room for further clarifying observations. Why only a small group of subjects should develop these reflex symptoms in the presence of injury has not been explained.

Both varieties of these neurovascular complexes, the compressive and reflex, may be disabling. The shoulder-hand syndrome tends to become a more serious disorder, because its progression to a disabled or even a useless extremity may be rapid, and the time for successful intervention short. The average case of any of the compression disorders is apt to be symptomatic over the course of many years and, in the absence of severe injury to vessels leading to thrombosis or embolism, generally does not lead to serious consequencies.

\section{Management of the Shoulder-Hand Syndrome}

Most of the treatment employed until recently was ineffectual. X-ray therapy to the cervicothoracic ganglia or to the shoulder and hand, physical modalities, ganglionic blocking agents and local infiltration of trigger points have been reported to be helpful in early cases. Graded exercises within the limits of tolerance undoubtedly should be initiated at all stages as an adjunct to any form of therapy. Effective early treatment is provided by serial stellate ganglion blocks, especially in the first and second stages often with complete or satisfactory remissons (and occasional relapses). With the advent of the corticosteroids, comparable results have been obtained with these compounds. A completely reliable form of treatment still is needed.

\section{Prevention}

An important consideration is the prevention of reflex phenomena, when possible. In conditions known to provoke reflex symptoms, such as external trauma, myocardial infarction, osteoarthritic neuropathy, hemiplegia, and others, it may be useful to introduce mobilizing exercises at the extremity as soon as practical, also analgesic infiltration of trigger points. Violent procedures to extremities presenting any suggestive symptoms are to be avoided. Alertness to early reflex neurovascular symptoms in underlying conditions predisposing to them should lead to early treatment which appears to prevent more severe developments.

\section{Differential Diagnosis of Neurovascular Disorders of the Shoulder}

Diagnostic evaluation requires a careful history and physical examination to investigate the characteristic pressure points and their features, given under the various headings. Apart from standard physical examination, these include inspection, palpation and postural tests for local 
TABLE 4

Diagnostic Features of Compression and Refles Neurovascular Syndromes of the Shoulder Girdle*

\begin{tabular}{|c|c|c|c|c|c|}
\hline & History & Pulse & Neurologic Signs & Diagnostic Test & Therapeutic Response \\
\hline $\begin{array}{l}\text { Costoclavicular } \\
\text { Syndrome }\end{array}$ & $\begin{array}{l}\text { Symptoms associated } \\
\text { with shoulders forc- } \\
\text { ed downward and } \\
\text { backward for long } \\
\text { periods }\end{array}$ & $\begin{array}{l}\text { Reduced in abnormal } \\
\text { shoulder position }\end{array}$ & $\begin{array}{l}\text { Usually except with } \\
\text { deformities }\end{array}$ & $\begin{array}{l}\text { Forced abnormal po- } \\
\text { sition of shoulder } \\
\text { reproduces signs } \\
\text { and symptoms }\end{array}$ & $\begin{array}{l}\text { Elimination of postu- } \\
\text { ral defects giving re- } \\
\text { lief }\end{array}$ \\
\hline $\begin{array}{l}\text { Hyperabduction } \\
\text { Syndrome (Costo- } \\
\text { clavicular Syndrome) }\end{array}$ & $\begin{array}{l}\text { Hyperabduction in } \\
\text { sleep or at work for } \\
\text { long periods }\end{array}$ & $\begin{array}{l}\text { Reduced in hyperabd. } \\
\text { (also B.P. and oscil- } \\
\text { lometry) }\end{array}$ & Often & $\begin{array}{l}\text { Hyperabduction re- } \\
\text { production of signs } \\
\text { and symptoms }\end{array}$ & $\begin{array}{l}\text { Correction of sleeping } \\
\text { or working position } \\
\text { giving relief }\end{array}$ \\
\hline $\begin{array}{l}\text { Scalenus Anticus } \\
\text { Syndrome and Cer- } \\
\text { vical Rib }\end{array}$ & $\begin{array}{l}\text { No special postural } \\
\text { features }\end{array}$ & $\begin{array}{l}\text { Reduced in resting } \\
\text { position or brought } \\
\text { on by Adson man- } \\
\text { oeuvre }\end{array}$ & $\begin{array}{l}\text { Reflexes occasionally } \\
\text { reduced on affected } \\
\text { side; noted weak- } \\
\text { ness in same }\end{array}$ & $\begin{array}{l}\text { Adson manoeuvre may } \\
\text { reproduce musculo- } \\
\text { skeletal, neuritic and } \\
\text { vascular signs. Ten- } \\
\text { der point at scalenus } \\
\text { area }\end{array}$ & $\begin{array}{l}\text { Correct injection of } \\
\text { procaine into ant. } \\
\text { scalenus may give re- } \\
\text { lief ; scalenotomy } \\
\text { often effective }\end{array}$ \\
\hline $\begin{array}{l}\text { Shoulder-Hand } \\
\text { Syndrome (Reflex } \\
\text { Dystrophy) }\end{array}$ & $\begin{array}{l}\text { Trauma, intrathor- } \\
\text { acic disease or idio- } \\
\text { pathic, no special } \\
\text { postural features }\end{array}$ & Sometimes reduced & $\begin{array}{l}\text { Increased or de- } \\
\text { creased reflexes of } \\
\text { part sometimes }\end{array}$ & $\begin{array}{l}\text { Stellate ganglion } \\
\text { block produces tran- } \\
\text { sient or prolonged } \\
\text { relief }\end{array}$ & $\begin{array}{l}\text { Repeated blocks or } \\
\text { corticosteroids; sym- } \\
\text { pathectomy effective } \\
\text { in earlier stages }\end{array}$ \\
\hline
\end{tabular}

-Symptoms common to some or all in each disorder: pain of shoulder, arm and/or hand; numbness, paresthesias of fingers; swelling of $\mathrm{O}$ hand(s), fingers; discoloration of hand(s); Raynaud's phenomenon; weakness of hand(s); supraclavicular bruit possible in compression disorders.

compression, cervical ribs, thoracic deformities, bulges or distortions in the supraclavicular area, evidence of vascular disturbance or disease; $\mathrm{X}$-ray films of the cervical spine (with oblique views), and of the shoulder and hand, if necessary, as well as special tests where bizarre compression may arise from tumour, enlarged lymph nodes, etc. The main differential points are summarized in Table 4.

The compression neurovascular disorders are the most easily understood from the mechanical standpoint. In all of them the production of symptoms is secondary to direct mechanical compression, of one anatomical variety or another, of the neurovascular bundle somewhere along the course of the cervico-axillary canal at the thoracic outlet, leading to distinctive forms of 'thoracic outlet syndromes.' The symptoms may arise from neural compression (usually the lower cords of the brachial plexus containing fibers from roots of $\mathrm{C} 8-\mathrm{T}_{\mathrm{I}}$ ) with the production of pain, paresthesias, hypalgesia or hyperesthesia and atrophy of muscles. Involvement of the vascular components may cause vasospastic phenomena with classical Raynaud's manifestations, ulceration, blanching of the skin, boring pain; in arterial compression, diminution of the pulse, difference in blood pressure, swelling, discoloration, even gangrene; with venous impingement, venous distention and edema. Thrombosis may occur at any time. In most instances removal of the compression results in eliminating the neurovascular symptoms, except where obviously permanent changes have occurred, as in thrombosis or embolism. Occasionally, severe vascular or neural compression may provoke superimposed reflex symptoms at the hand or possibly a shoulder-hand syndrome, creating a complex situation for an observer who has not followed the evolution of the clinical picture. When musculoskeletal or neuros muscular symptoms predominate, intrinsic dis orders of the shoulder or neuropathy must be differentiated, most frequently cervical disco? genetic or osteoarthritic pathology.

The reflex neurovascular disorders, as exemplified by the shoulder-hand syndrome, generally differ characteristically from the compression syndromes in causation, manifestations and therapy. The reflex clinical picture usually is secondary to initial injury, by either internal or external trauma, with a reflex neurovascular reaction mediated by a complicated spinal cord reflex. The tissue disturbance tends to be localized at the shoulder and hand. It is reflected in various degrees and combinations of pain, disability, vasomotor fluctuations, swelling, edema, spotty osteoporosis and deforming trophic changes. The shoulder-hand syndrome is more likely to simulate some form of rheumatic disorder, such as rheumatoid arthritis, bursitis, gout or scleroderma. When it is in mild form, or when neuritic symptoms are impressive, and especially when there are localized reflex neurovascular symptoms, as in circumscribed hand involvement, the question of excluding compressive neurovascular disorders is more apt to arise.

For references see page 412 . 


\section{The Shoulder-Hand Syndrome}

The shoulder-hand syndrome consists of pain, stiffness and limitation of movement of the shoulder, hand and fingers, and trophic changes in the skin and other tissues of the hand, following acute cardiac infarction. The complete picture is uncommon, occurring in less than 5 per cent. of infarctions. Some degree of stiffness of one or both shoulders develops in about 10 per cent. of patients within a month or six weeks of an acute infarction.

In the mildest form of the syndrome, the patient complains of slight pain or stiffness on moving the arm. Severe limitation of movement with pain shooting down the arm, upwards to the neck and down the side of the thorax on abduction and lateral rotation is known as a 'frozen shoulder.' In some cases the hand is warm and the fingers pulsate, reflecting vaso-dilation. These changes may be the forerunners of severe, if uncommon trophic changes, namely swelling of the fingers and hand, stretching of the skin with red-purple discoloration, trophic ulceration of the fingers or hand, and thickening and contracture of the palmar aponeurosis. The condition in any degree of severity except the slightest, may be very resistant to treatment and sometimes the results of months of painstaking physiotherapy may be disappointing. Occasionally, all stiffness and pain may disappear spontaneously within a few weeks.

The shoulder-hand syndrome has not been satisfactorily explained. The changes show a tendency to appear in joints which have been the seat of arthritis or peri-arthritis. The left arm is the more often affected but the right arm is involved when the ischaemic pain was right-sided. Protective disuse of the limb is responsible to some extent, but other factors are involved, too. One of these is a neurovascular reflex mechanism. Pain impulses arising from the heart, reflexly produce muscular spasm and neuro-vascular reactions in the ligaments, muscles and skin, innervated by the eighth cervical to the fourth thoracic spinal segments.

\section{Treatment}

No special treatment is needed for the pain of acute infarction referred to the arm. The mild 0 varieties of the shoulder-hand syndrome usually yield to passive and active shoulder and arm exercises. The more severe degrees are often long-lasting and resistant to treatment. If the infarction heals satisfactorily and pain does not recur, the shoulder stiffness may subside spontaneously in a few months. Sometimes it may still cause trouble after a year. In addition to physiotherapy the various measures used include procaine infiltration around the shoulder joint, steroid therapy, upper thoracic sympathetic block with procaine and stellate ganglionectomy. These points are considered fully in other parts of this symposium.

\section{Summary}

The typical chest pain of ischaemic heart $\vec{c}$ disease (angina pectoris and cardiac infarction) is often transmitted to one or both shoulders and $\vec{\varphi}$ arms. Occasionally, it is felt first in the forearm of or arm and spreads upwards to the shoulder and across the chest. Rarely, it may be confined to thêे arms. The correct diagnosis may be missed when the pain is dominantly in the arms or shoulders.

The shoulder-hand syndrome is an uncommon sequela of acute cardiac infarction. It consists of stiffness of the shoulder, and in its severe form, of great pain on moving the arm and trophic changes in the hand. The condition may respond only slowly to treatment, and may be troublesome for many months after an acute infarction.

\section{BIBLIOGRAPHY}

HEBERDEN, W. (1772), Med. Trans. Roy. Coll. Phys., 2, 59. HERRICK, J. B. (1912), f. Amer. med. Ass., 59, 2015.

References from page 404-H. Harold Friedman, M.D., Thomas G. Argyros, M.D., and Otto Steinbrocker, M.D. 会 REFERENCES

I. ADSON, A. W., and COFFEY, J. R. (1927): 'Cervical rib, method of anterior approach for relief of symptoms by division of scalenus anticus,' Ann. Surg., 85, 839 .

2. BEYER, J. A., and WRIGHT, I. S. (1951): "The hyperabduction syndrome with special reference to its relationship to Raynaud's syndrome,' Circulation (N.Y.), 4, No. 2.

3. EDEN, K. C. (r939): 'The vascular complications of cervical ribs and first thoracic rib abnormalities,' Brit. $f$. Surg., 27, III.

4. EDWARDS, E. A., and LEVINE, H. D. (1942): ' Auscultation in the diagnosis of compression of the subclavian artery,' New Eng. F. Med., 247, 79.

5. FALCONER, M. A., and WEDDELL, G. (1943): ' Costoclavicular compression of the subclavian artery and vein,' Lancet, 245, 539.

6. FALCONER, M. A. (1947): 'The costoclavicular syndrome,' correspondence, Brit. Med. F., July 12.

7. FISKE, L. G. (1952): 'Brachial plexus irritation due to hyper- N trophied omohyoid muscle,' $\mathfrak{F} . A . M . A ., 149,758$.

8. GAMBLE, S. G. (1951): 'Costoclavicular syndrome,' Arch. N phys. Med., August, $516-522$.

9. HAGGERT, G. E. (1948): 'Value of conservative management $\mathrm{W}$ in cervicobrachial pain, ' F.A.M.A., 137, 508-513.

10. JUDOVICH, B., BATES, W., and DRAYTON, W., Jr. (1944): 'Pain in the shoulder and upper extremity due to 6 scalenus anticus syndrome,' Amer. F. Surg., 63, No. 3, $\frac{\mathrm{C}}{\mathbb{D}}$
March.

Ir. LORD, J. W., Jr., and ROSATI, L. M. (1958): ' Neurovascular $\stackrel{\text { ? }}{+}$ compression syndromes of the upper extremity,' Clin. Symp., I0, No. 2, March-April.

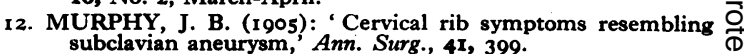

13. MURPHY, T. (1910): 'Brachial neuritis from pressure of the first rib,' Aust. med. F., 15, 582-585.

References continued on page 425 
associated with a relaxation in aseptic techniques, is responsible for the emergence of and infections with, the 'Hospital Staphylococcus': an antibiotic-resistant strain, apparently more virulent than its predecessors, liable to cause large-scale epidemics, extremely well adapted for cross-infection by its ability to survive the most adverse conditions and particularly liable to produce a carrier-state. Its exact mode of spread is still obscure but direct contact plays an important part. A hospital staphylococcal infection carries the twofold danger of virulence and antibiotic resistance. For this reason the problem is now as serious as it was in the pre-antibiotic era, with other virulent organisms now replaced by the hospital staphylococcus. The problem is largely preventable by strict control measures aimed at limiting the use of antibiotics, and a return to strict aseptic and cross-infection precautions. The infected 'case must be considered as a real source of danger to himself and to others.

\section{Acknowledgment}

I' should like to thank Professor J. B. Kinmonth for kindly reading this paper and making helpful criticisms.

\section{BIBLIOGRAPHY}

Annotation (1958), Lancet, 11, 1110.

Annotation (1959), Ibid., i, 34 .

BARBER, M. (1957), in 'Drug Resistance in Micro-organisms,' edited by G. W. Wolstenholme and C. M. O'Connor, London.

BRODIE, J., KERR, M. R., and SOMMERVILLE, T. (1956), Lancet, i, ig.

BURNETT, W., MCDONALD, S., and TIMBURY, M. C. (1958), Scot. med. F., 3, 392.
BURNETT, W. E., CASWELL, H. T., SCHREK, K. M., CARRINGTON, E. R., LEARNER, N., STEEL, H. H., TYSON, R. R., and WRIG̈HT, W. C. (1958), F. Amer. med. Ass., 166, 1183 .

CASWELL, H. T., SCHREK, K. M., BURNETT, W. E. CARRINGTON, E. R., LEARNER, N., STEEL, H. H., TYSON, R. R., and WRIGHT, W. C. (1958), Surg. Gynec. Obstet., I06, 1 .

CLARKE, S., DALGLEISH, P. G., and GILLEPSIE, W. A. (1952), Lancet, i, II 32 .

CLARKE, S. K. R. (1957), Brit. F. Surg., 44, 592.

DINEEN, P., and PEARCE, C. (1958), Surg. Gynec. Obstet. I06, 453.

Editorial (1958), Brit. med. F., i, 207.

Editorial (1958), Lancet, i, 515.

GILLEPSIE, W. A., SIMPSON, K., and TOZER, R. (1958), Ibid., ii, 1075 .

GODFREY, M. E., and SMITH, I. M. (1958), f. Amer. med. Ass., 166, 1197.

GOULD, J. C. (1958), Lancet, i, 489.

HARE, R., and RIDLEY, M. (1958), Brit. med. F., i, 69.

JEFFREY, J. S., and SKLAROFF, S. A. (1958), Lancet, i, 365.

KINMONTH, J. B., HARE, R., TRACY, G. D., THOMAS, C. G. A., MARSH, J. D., and JANTET, G. H. (1958), Brit. med. f., 2, 407.

LANGMUIR, A. D. (1958), f. Amer. med. Ass., 166, 1202.

Leading Article (1958), Lancet, i, 250.

Leading Article (1958), Ibid., ii, 1 106.

LOH, W. P., and STREET, R. B. (1957), New Engl. F. Med., 256, 177 .

PETERSDORF, R. G., CURTIN, J. A., HOEPRICK, P. D., PEELER, R. N., and BENNETT, I. L.' (I957), Ibid., 257, IO0I.'

RAVENHOLT, R. T., and LA VECK, G. D. (1956), Amer. $\mathcal{F}$. Publ. Hlth, 46, 1287 .

RAVENHOLT, R. T., WRIGHT, P., and MULHERN, $M$. (1957), New Engl. भै. Med., 257, 789.

ROBERTSON, H. R. (1958), Ann. Roy. Coll. Surg., 23, 141.

ROWNTREE, P. M., and FREEMAN, B. M. (1955), Med.F. Aust., 2, 157.

SHOOTER, R. A. (1958), Ann. Roy. Coll. Surg., 23, 312.

SHOOTER, R. A., SMITH, M. A., GRIFFITHS, J. D., BROWN M. E. A., WILLIAMS, R.' E. O., RIPPON, J. E., and JEVANS, M. P. (1958), Brit. med. $\ddot{\mathcal{F}}$., i, 607 .

SHOOTER, R. A., TAYLOR, G. W., ELLIS, G., and ROSS, J. P. (1956), Surg. Gynec. Obstet., 103, 257.

TIMBURY, M. C., WILSON, T. S., HUTCHISON, J. G. P., and GOVAN, A. D. T. (1958), Lancet, ii, 1081.

WISE, R. I. (1958), F. Amer. med. Ass., 166, 1178.

WYSHAM, D. N., and KIRBY, W. M. (1957), Ibid., 164, 1733.

References continued from page 412-H. Harold Friedman, M.D. Thomas G. Argyros, M.D., and Otto Stienbrocker, M.D.

14. NAFFZIGER, H. C., and GRANT, W. T. (1938): 'Neuritis of the brachial plexus, mechanical in origin: the scalenus syndrome,' Surg. Gynec. Obstet., 67, 722.

15. OCHSNER, A., GAGE, M., and DEBAKEY, M. (1935): 'Scalenus anticus (Naffziger) syndrome,' Amer. F. Surg.,

16. PAULL, R. (1946): 'The neurovascular syndrome as manifested in the upper extremities, Amer. Heart $\mathcal{F}_{\text {., } 32,32 .}$

17. PEET, R., HENRIKSEN, J. D., and ANDERSON, M. G. M. (1956):' Thoracic outlet syndrome: evaluation of a therapeutic exercise programme,' Staff Meet. Mayo Clin., May 2.

18. RAAF, J. (1955): 'Surgery for cervical rib and scalenus anticus syndrome,' $\mathcal{Y}$.A.M.A., 157, $219-223$.

19. STAMMERS, F. A. R. (1950): 'Pain in the upper limb from mechanisms in the costoclavicular space,' Lancet, April $\mathrm{I}$.

20. STEINBROCKER, O., SPITZER, N., and FRIEDMAN, H. H. (1948): " The shoulder-hand syndrome in reflex dystrophy of the upper extremity,'Ann. intern. Med., 29, 22.

21. STEINBROCKER, O., and ARGYROS, T. G. (1958): 'The shoulder-hand syndrome: Present status as a diagnostic and therapeutic entity,' Med. Clin. N. Amer., November.
22. STEINBROCKER, O., NEUSTADT, D, and BOSCH, $S$. (1955): 'Painful shoulder syndromes; their diagnosis and treatment,' Ibid., 39, No. 2, I.

23. TELFORD, E. D., and MOTTERSHEAD, S. (1947): 'The "costoclavicular syndrome," "Brit. med. $\dot{F}$., 1, 325-328, March 15.

24. THEIS, F. V. (1939): 'Scalenus anticus syndrome and cervical ribs,' Surgery, 6, No. I, $112-125$.

25. COOTE and LAW, cited in UPMALIS, I. H. (r958): ' The scalenus anticus and related syndromes,' Surg. Gynec. Obstet. with Int. Abstr. Surg., 107, No. 6, December.

26. WALSHE, F. M. R. (1951): 'Nervous and vascular pressure syndromes of the thoracic inlet and cervico-axillary canal. 'Modern Trends in Neurology,' p. 542. Edited by A. Feiling. Butterworth, London.

27. WILLSHIRE ( 1860 ): Referred to in clinical records, 'Supernumerary first rib,' Lancet, ii, 633 .

28. WRIGHT, I. S. (1945): 'The neurovascular syndrome produced by hyperabduction of the arms,' Amer. Heart $\mathcal{F}$., 29, 1 . 